\title{
OS GRUPOS INDÍGENAS E OS DOCES BRASILEIROS
}

MÁRTIN CÉSAR TEMPASS ${ }^{1}$

UFRGS

RESUMO: Nas obras de Gilberto Freyre e Câmara Cascudo, que tanto influenciaram a literatura sobre a alimentação brasileira, a participação dos grupos indígenas no processo de formação da doçaria nacional é negligenciada. Contudo, é possivel encontrar nas "entrelinhas" das obras destes dois autores valiosas informações sobre as contribuições indígenas a este processo. A partir destes dois autores e baseado na noção de sistemas culinários, o presente artigo busca situar o papel dos grupos indígenas na formação da doçaria brasileira e elencar as possiveis razões para a invisibilidade da doçaria de origem indígena no processo de formação da culinária nacional.

PALAVRAS-CHAVE: Grupos indígenas; sistemas culinários; doçaria; culinária brasileira.

ABSTRACT: In the books of Gilberto Freyre and Câmara Cascudo, that influencied so much the literature about brazilian alimentation, the participation of indigenous groups in the national sweets formation process is negligencied. However, is possible to find in book's "interlineations" of these two authors valuables informations about indigenous contributions to this process. Starting from these two authors and based in the culinary system notion, this paper quests to situate the role of indigenous groups in the brazilian sweets formation and numbers the possibles causes to invisibility of sweets by indigenous at the culinary formation process.

KEYWORDS: Indigenous groups; Cuisine system; Sweets; brazilian culinary.

Há um gosto todo especial em fazer preparar um pudim ou um bolo por uma receita velha de avó. Sentir que o doce cujo sabor alegra o menino ou a moça de hoje já alegrou o paladar da dindinha morta que apenas se conhece de algum retrato pálido mas que foi também menina, moça e alegre. Que é um doce de pedigree, e não um doce improvisado ou imitado dos estrangeiros. Que tem história. Que tem passado. Que já é profundamente nosso. Profundamente brasileiro. Gostado, saboreado, consagrado por várias gerações brasileiras. Amaciado pelo paladar dos nossos avós. Servido em potes indígenas, em terrinas patriarcais; enfeitado de papel azul, cor-de-rosa, amarelo, verde, picado ou rendilhado segundo modelos de outros

\footnotetext{
${ }^{1}$ Doutorando em Antropologia Social - PPGAS/UFRGS. E-mail: potz 51@yahoo.com.br .
} 
séculos; recortado em corações, meias-luas, estrelas, cavalinhos, patinhos, vaquinhas, segundo velhas fôrmas sentimentais (FREYRE, 1997, p. 64).

$\mathrm{Na}$ literatura que trata sobre a formação da culinária brasileira, desde as obras mais clássicas até as mais recentes, nos é informado que as "três raças" formadoras do povo brasileiro - negros, índios e brancos - contribuíram significativamente para a formação da agora chamada "cozinha brasileira". As cozinheiras negras e brancas criaram os pratos da culinária nacional valendo-se - também - dos ingredientes indígenas. Contudo, essa informação que nos é passada pela literatura precisa ser revista. Os indígenas, mais do que simples ingredientes, forneceram um complexo savoir-faire para a culinária brasileira. Ao contrário do que aponta a literatura, os "conquistadores" europeus, ao desembarcar no Brasil, se valeram dos "sistemas culinários" dos grupos indígenas. Foi a adoção destes sistemas culinários que possibilitou a fixação dos primeiros europeus na terra recém "descoberta" e tornou viável a colonização do Brasil (TEMPASS, 2008).

Sobre sistemas culinários, ou alimentares, Jesús Contreras Hernández e Mabel Gracia Arnáiz (2005) apontam o seguinte:

... debemos entender por sistema alimentario el carácter complejo de las relaciones interdependientes asociadas a la producción, distribución y consumo de los alimentos que se han ido estableciendo a lo largo del tiempo y del espacio con el fin de resolver los requerimientos alimentarios de las poblaciones humanas. De este modo, se reconoce la relación entre las diferentes fuerzas que actúan en los flujos de mercancías que van desde los productores a los consumidores y se acepta, por otra parte, que los sistemas alimentarios son realidades dinámicas, en las que se dan elementos de continuidad y de cambio a partir de la evolución de los procesos sociales que delimitan las formas en que los alimentos son producidos, distribuidos y consumidos (HERNÁNDEZ e ARNÁIZ, 2005, p. 102-103).

Ao empregar a noção de sistema culinário estamos, de forma holística, levando em conta todo tipo de encadeamento acionado para que possamos ingerir um prato de comida. Os alimentos são "parte inseparável de um sistema articulado de relações sociais e de 
significados coletivamente partilhados" (GONÇALVES, 2002, p. 9). Podemos ter uma idéia melhor da magnitude deste sistema a partir dos itens listados por José Reginaldo Santos Gonçalves (2002), componentes dos sistemas culinários:

a) processos de obtenção dos alimentos (caça, pesca, coleta, agricultura, criação, troca ou comércio);

b) seleção de alimentos (sólidos e líquidos, doces e salgados, etc.);

c) processos de preparação (cozimento, fritura, temperos, etc.);

d) saberes culinários;

e) modos de apresentar e servir os alimentos (marcados pela formalidade ou pela informalidade);

f) técnicas corporais necessárias ao consumo de alimentos (maneiras à mesa);

g) 'refeições', isto é, situações sociais (quotidianas e rituais) em que se preparam, exibem e consomem determinados alimentos;

h) hierarquia das refeições;

i) quem oferece e quem recebe uma 'refeição' (quotidiana ou ritual);

j) classificação de comidas principais, complementares e sobremesas;

k) equipamentos culinários e como são representados (espaços, mesas, cadeiras, esteiras, talheres, panelas, pratos, etc.);

I) classificação do 'paladar';

m) modos de dispor dos restos alimentares; etc. (GONÇALVES, 2002, p. 9-10 - grifos no original).

A partir da noção de sistema culinário, acima exposta, é objetivo deste artigo mapear a participação indígena na formação da doçaria brasileira, bem como as razões para que a literatura negligencie esta importância.

O Brasil teve seu advento com a indústria açucareira. Com um mercado altamente rentável, todos os esforços foram concentrados para a produção de açúcar. Assim, a monocultura do açúcar dominou a paisagem brasileira, enquanto que o cultivo de outros gêneros alimentícios foi deixado de lado. No Brasil abundava o açúcar e faltavam os demais gêneros alimentícios (FREYRE, 1966). E, como afirma Câmara Cascudo, "o açúcar provoca o doce" (CASCUDO, 1983, p. 648). Desta forma, não é de se estranhar que inúmeros doces fossem criados em 
terras brasileiras a ponto de se tornarem parte da identidade nacional (FREYRE, 1997 e 1966; CASCUDO, 1967, 1972, 1983; LÉPINE, 2003; LOKSCHIN, 2005).

No Brasil "desenvolveu-se uma arte de doces que se situa entre as mais características da civilização brasileira" (FREYRE, 1997, p. 17). "O açúcar [...] adoçou tantos aspectos da vida brasileira que não se pode separar dele a civilização nacional" (FREYRE, 1997, p. 55). Os "doces" brasileiros são exageradamente doces, muito mais "doces" que os "doces" de outros países. A doçaria brasileira foi herdada dos portugueses $^{2}$ e estes já se valiam de um excesso de açúcar desde a Idade Média. Com a abundância de açúcar no Brasil, isso se acentuou ainda mais. Era tanto açúcar que, segundo o relato de cronistas que provaram doces brasileiros de frutas, não se conseguia distinguir 0 sabor entre uma fruta e outra ${ }^{3}$. Além da extrema doçura dos seus doces, os brasileiros também se destacam pela variedade e quantidade de produção destes. Por muito tempo a produção brasileira de doces superou em absoluto a de todos os mercados do mundo. O doce era comida cotidiana. Muitos "brasileiros" faziam todas as suas refeições apenas consumindo doces (FREYRE, 1997; CASCUDO, 1983; SILVA, 2005). "Nunca um brasileiro dispensou o adoçar a boca depois de salgar o estômago. [...]. Com açúcar e mel até as pedras sabem bem. [...]. De amargo, basta a vida" (CASCUDO, 1967).

Mas, qual a parcela de contribuição dos grupos indígenas no processo de construção deste "império do doce"? Os indígenas desempenharam um importante papel na colonização do Brasil e contribuíram, e muito, no processo de formação da culinária brasileira. Contribuíram com os seus sistemas culinários (TEMPASS, 2008). Insistindo com a noção de sistema, seria possível isolar os doces dos sistemas culinários? Se os doces são elementos do sistema e os indígenas contribuíram com seus sistemas, logo os indígenas também participaram do desenvolvimento da doçaria nacional. Vamos detalhar mais esta noção a seguir. Para tanto, utilizaremos as obras de Gilberto Freyre e Luis da Câmara Cascudo como fio condutor, em função da

\footnotetext{
${ }^{2}$ Como se pretende mostrar mais adiante, a doçaria não foi apenas uma herança portuguesa, os indígenas também contribuíram neste sentido.

${ }^{3} \mathrm{Na}$ atualidade, os brasileiros ainda comem doces em excesso, sendo os seus doces muitos mais doces que os de outras nações (FREYRE, 1997).
} 
reconhecida influência destes autores sobre os demais trabalhos que tangem a formação da culinária brasileira.

As obras destes dois autores negligenciam a doçaria indígena. Mas - estranho - é também nas obras de Freyre e Cascudo que, nas "entrelinhas", podemos obter alguns dados relevantes da produção doceira dos grupos indígenas brasileiros.

Gilberto Freyre (1966 e 1997) não chega a afirmar literalmente que os indígenas não consumiam doces, mas, ao traçar as origens da doçaria brasileira não inclui os indígenas na análise e, por outro lado, abusa de alusões as contribuições lusas e africanas neste sentido. Ou melhor, Freyre (1966 e 1997) até reconhece alguma contribuição indígena, mas esta se resume ao simples fornecimento de ingredientes. Em outras palavras: na visão de Freyre os indígenas fornecem seus ingredientes e os africanos e portugueses aplicam o savoir-faire, criando os doces da culinária brasileira. Sobre isso cabe a observação de que Freyre enfatiza fortemente, além da portuguesa, a contribuição africana. Segundo Gilberto Freyre (1966), o gênio da criação dos doces e das guloseimas de açúcar foi mais da escrava africana do que da senhora branca. Segundo o autor, "o legítimo doce ou quitute de tabuleiro foi o das negras forras. $O$ das negras doceiras. Doce feito ou preparado por elas" (FREYRE, 1966, p. 636). Foram as negras que introduziram os produtos locais na doçaria. Já no livro "Açúcar: uma sociologia do doce", Gilberto Freyre (1997) expõem a versão de que foram as portuguesas as responsáveis pela introdução dos ingredientes locais na doçaria brasileira. Então, para os efeitos do presente artigo, vamos considerar que tanto africanas como portuguesas mesclaram o açúcar com ingredientes locais e criaram novos doces. O importante - e que pretendemos contestar mais adiante - é que Gilberto Freyre exclui as indígenas do processo criativo da doçaria brasileira.

Câmara Cascudo era enfático na afirmação de que os indígenas não consumiam/produziam doces. Selecionamos os seguintes trechos para ilustrar a posição do autor:

Os indígenas tinham bebida de milho, menos fermentada e sem doce, como geralmente os vinhos africanos nativos (CASCUDO, 1983, p. 815). 
Devemos aos portugueses, e não aos amerabas e africanos que o ignoravam, esse possível abuso do açúcar (CASCUDO, 1983, p. 649).

Nem os pretos e nem os amerabas faziam doces ... (CASCUDO, 1983, p. 640).

Imagino o negro, o indígena, enchendo a boca com o primeiro torrão de açúcar mascavado (CASCUDO, 1967, p. 270).

Seria pela mão portuguesa que amerabas e africanos no Brasil conheceriam os dois pólos sensíveis do paladar: - o açúcar e o sal (CASCUDO, 1967, p. 238).

Nem açúcar e nem sal, valores da mulher branca, foram ciência afro-brasiliense. [...]. A cunhã fracassou no domínio do açúcar. [...]. Nenhum doce the nasceu das mãos generosas (CASCUDO, 1967, p. 167).

Ovo e açúcar jamais foram intimidades negras e indígenas (CASCUDO, 1972, p. 34).

Indígenas brasileiros e escravos africanos provaram o açúcar quando os primeiros engenhos funcionaram no Brasil. Nenhum doce se originou entre os pretos e os amerabas, mesmo depois da nossa indústria funcionar. A doçaria é uma presença da mulher portuguesa, valorizando pelo uso as maravilhas do solo americano, a goma da mandioca, os frutos para marmeladas, termo genérico, compotas, doces cristalizados, que já exportavam em 1610 (CASCUDO, 1972, p. 26).

Câmara Cascudo $(1967,1972,1983)$, muito mais polêmico e contraditório, argumentava que os indígenas comiam simplesmente para se sustentar ${ }^{4}$. E, como para nós, não índios, o doce não representa sustento (o doce, enquanto nutriente, é considerado supérfluo), Câmara Cascudo (1967) concluiu que os indígenas não consumiam doces. Ele diverge de Gilberto Freyre quanto ao papel dos africanos na doçaria brasileira, designando unicamente as portuguesas para a ação inventiva dos doces nacionais, conforme indicam as citações reproduzidas acima.

\footnotetext{
${ }^{4} \mathrm{O}$ autor afirma não tratar da escassez e da fome, mas da comida e do paladar. Trata da culinária, tida como ciência agradável e inseparável da vida humana. É desta forma que aborda os portugueses e africanos na construção da cozinha brasileira. Mas, no que tange aos grupos indígenas, Câmara Cascudo deixa a culinária e o paladar de lado e tece um discurso sobre a escassez e a fome. O paladar inexiste nos indígenas, tudo o que é consumido serve apenas para o sustento. Aos indígenas falta tudo. Falta óleo, doces, sal, acompanhamentos, ovos, leite, frituras, comensalidade, etc.
}

Espaço Ameríndio, Porto Alegre, v. 2, n. 2, p. 98-114, jul./dez. 2008. 
As concepções destes autores influenciaram, e muito, obras mais recentes sobre a temática, que continuam ignorando qualquer contribuição indígena à doçaria brasileira ${ }^{5}$. Em outra publicação recente, José Martins Catharino, realizador de uma ampla pesquisa bibliográfica sobre os grupos indígenas brasileiros, incluindo os relatos dos primeiros cronistas, afirma que: "a culinária índia desconhecia o preparo de sobremesas, isto é, doces, pois o açúcar era desconhecido. Quanto a isso, a contribuição portuguesa foi das maiores, inclusive para as cáries ..." (CATHARINO, 1995, p. 354).

No entanto, nas "entrelinhas" das obras de Gilberto Freyre (1966 e 1997) e Luis da Câmara Cascudo (1967, 1972 e 1983) aparecem argumentos que, ao contrário, evidenciam a produção e o consumo de doces pelos indígenas ${ }^{6}$. Primeiramente, voltando à noção de sistema culinário, como referido anteriormente, os colonizadores adotaram - se inseriram - os sistemas culinários dos grupos indígenas para poderem se fixar no Brasil. A alimentação brasileira no período já se caracterizava pelo consumo excessivo de doces. Mas, segundo os autores referidos, os indígenas não comiam doces. Como isso é possível?

Gilberto Freyre (1966) destaca o consumo de mel pelos indígenas. O mel era tão apreciado que os indígenas domesticavam as abelhas ${ }^{7}$. Ao falar sobre a farinha de mandioca, alimento indígena, o autor afirma que esta era "muito doce e saborosa". Sobre as frutas da terra, apreciadas pelos indígenas, Gilberto Freyre escreve:

Todas, frutas produtoras de um açúcar que pelos indígenas de algumas dessas terras, constituídos em sociedades primitivas, vinha sendo - e é ainda, embora a ocorrência seja hoje rara - consumido mais como fruta do que como matéria manufaturada. Ao que se acrescentara, entre tais primitivos, o consumo de açúcar sob a forma de mel de abelha ${ }^{8}$ (FREYRE, 1997, p. 12 - grifos meus).

\footnotetext{
${ }^{5}$ Para citar algumas: Couto (2007), Leal (2007) e Franco (2006).

${ }^{6}$ É importante ressaltar que, tanto Gilberto Freyre quanto Câmara Cascudo, se referem de uma forma geral à alimentação dos indígenas, passando a idéia de que todos os diferentes grupos se alimentam de foram similar. Trata-se de um equívoco destes autores, pois, culturas distintas, culinárias distintas.

7 A domesticação das abelhas é uma exceção, pois tradicionalmente os grupos indígenas não domesticavam animais. Sobre isso ver Descola (1998).

${ }^{8} \mathrm{Na}$ mesma obra, mais adiante, Gilberto Freyre (1997) afirma que as frutas brasileiras tinham um sabor "acre". Voltaremos a este ponto mais adiante.
} 
Câmara Cascudo também destaca o apreço dos indígenas pelo mel. O índio "deixou-nos a apicultura. A doce herança do mel" (CASCUDO, 1967, p. 164). Sobre o preparo do cauim o autor relata que "na diástase da saliva a ptialina transforma o amido das raízes e dos frutos em maltose e dextrina, provocando a sacarificação, resultante dos ácidos orgânicos sobre os açúcares" (CASCUDO, 1967, p. 136 - grifos meus). O cauim é doce. Sobre o beiju Cascudo escreve que ele "fundou [...] a dinastia dos bolos nacionais" (CASCUDO, 1967, p. 164). Entre 1570 e 1584, Gabriel Soares de Souza, segundo relato de Cascudo, "denunciava as habilidades das moças indígenas para fazerem cousas doces" (CASCUDO, 1967, p. 165).

Paula Pinto e Silva (2005) apresenta um argumento que evidencia o consumo de doces pelos indígenas. Segundo a autora,

Os beijus indígenas eram em tudo parecidos com o filhós portugueses, tanto em sua forma redonda quanto no gosto insosso e aderente à boca. Eram comidos geralmente pela manhã, regados com mel de pau ou mel silvestre, fazendo as vezes de bolo e pão, ou mesmo entre as refeições principais, numa espécie de merenda (SILVA, 2005, p. 85).

Enfim, com os argumentos acima apresentados, fica difícil afirmar que os indígenas não preparavam e consumiam doces. Então, porque tal noção se estabeleceu? Primeiramente, julgo eu, deve-se a uma confusão de categorias. Freyre e Cascudo não estão falando do "sabor" doce, mas sim de uma gama de pratos que tem a intenção de adoçar o paladar de quem os consome. Falam de um "sabor" doce com formato e status "específico". Na visão destes autores, todo "Doce" é "doce", mas nem todo "doce" é "Doce". De forma menos confusa, todo "Doce" possui o sabor "doce", mais nem tudo o que possui o sabor "doce", na visão destes autores, é considerado um "Doce". Alfenins e bananas são doces, o primeiro é um tipo de "Doce", o segundo possui o sabor "doce". "Doce" é um estilo, uma etiqueta; "doce" é um sabor.

Que é doce, afinal? Dizem os dicionários que é aquilo que tem um sabor como o de açúcar ou de mel; e que, assim sacarino, não é amargo, nem salgado, nem picante; e - ainda - a composição que é temperada com açúcar, mel ou outro ingrediente sacarino. À base 
dessas composições é que, para o sociólogo da cultura, há uma doçaria, uma confeitaria, uma pastelaria, uma estética de sobremesa com implicações socioculturais: toda uma parte da arte-ciência da culinária com um estilo, uma etiqueta, uma forma de ser alimentação sendo também recreação que diferencia da outra; que se vem constituindo em objeto autônomo de estudo etnológico e de estudo histórico para começar a ser já - mais do que isto - objeto de estudo sociológico. Há uma sociologia do doce à parte de uma sociologia de arte da cozinha e do que esta arte - mais vasta implica de sociocultural (FREYRE, 1997, p. 48 - grifos meus).

Isso leva a muitas outras considerações. Uma fruta, por exemplo, que tem sabor "doce" pode se tornar um "Doce". Gilberto Freyre (1997) e Câmara Cascudo (1967 e 1983) destacam que as frutas brasileiras possuíam um gosto fortemente acre, azedo, áspero, picante, "esquisitamente tropical". Segundo Freyre (1997), os colonizadores só conseguiam comer estas frutas quando acrescidas de açúcar ou mel. Cascudo (1967 e 1983) afirma que estas mesmas frutas se tornaram mais doces com o advento da agricultura, podendo ser consumidas com apreço. As frutas plantadas são muito mais doces do que as colhidas no mato. Contudo, os índios coletam as suas frutas no mato. Suas frutas são, na concepção destes autores, acres, ácidas, ásperas, etc. Gilberto Freyre coloca a seguinte questão: "não haverá, da parte de certos apreciadores de 'doces ácidos', certo masoquismo do paladar?" (1997, p. 45 - grifos no original).

Não creio que as frutas típicas brasileiras, hoje tão elogiadas pela sua doçura, pudessem ter tido o sabor acima descrito. Julgo que as frutas brasileiras sempre tiveram o sabor doce. Mas, mesmo admitindo a hipótese levantada, Câmara Cascudo (1967 e 1983) apresenta uma forma encontrada pelos grupos indígenas para acentuar o sabor adocicado de seus alimentos. Segundo este autor, entre os grupos indígenas (de forma geral) o usual era assarem os seus alimentos e os poucos que eram cozidos ficavam horas em ebulição. Isso para carnes, tubérculos, cereais e frutas. A cocção por várias horas seguidas concentra o sabor doce dos alimentos. "As frutas verdes eram assadas. Eliminavam o excesso aquoso e fixavam pelo calor os amidos e fenóis superiores. Ananases, bananas, mamões, mangabas, jenipapos ainda 
MÁRTIN CÉSAR TEMPASS - Os grupos indígenas e os doces brasileiros

são assados pelo povo [indígena], ficando macios e mais doces" (CASCUDO, 1967, p. 153 - grifo meu).

Este procedimento, assar as frutas com a intenção de ressaltar o seu sabor adocicado, pode ser considerado um tipo de "Doce"? Depende. Na nossa concepção ocidental, o "Doce" está relacionado com o momento e a maneira de ser consumido. Nós não fazemos uma refeição unicamente com "Doces". Para nós o Doce é em menor quantidade e apenas no final das refeições.

Nós, não-índios, separamos o doce do salgado. Como apontado por Flandrin, "au niveau des representations, un plat doit être "sucré" ou "salé", et nous, Français, sommes desorientes si nous ne pouvons classer ce que nous mangeons d'un côté ou de l'autre" (FLANDRIN, 1993, p. 152). É uma classificação da "civilização ocidental" separar o salgado do doce; o mais nutritivo, do menos nutritivo; o alimento do início das refeições, do alimento do final das refeições; o alimento que sustenta, do alimento que "apenas engana o estômago". O "Doce" é uma categoria ocidental que não se aplica a todos os pratos adocicados.

No entanto, entre os grupos indígenas não existe esta categorização $^{10}$. Assim, de forma etnocêntrica, sem perceber que os indígenas possuem uma categorização diferente de doces, se difundiu a noção de que os indígenas não consumiam doces. Como explicitado acima, através de dados de Freyre e Cascudo, os indígenas consumiam alimentos de sabor adocicado, não só os consumiam como faziam isso em excesso. Faziam isso em praticamente todas as refeições.

Como já comentado, os indígenas preferiam assar seus alimentos em detrimento da cocção. Os poucos alimentos que eram cozidos ficavam por várias horas sobre o fogo. Isso se aplicava para todo tipo de alimento. Estes dois procedimentos resultam em uma eliminação da porção aquosa e na concentração do sabor doce nos alimentos. Assim, pode-se especular que todas - ou quase todas - as comidas dos índios tinham a tendência de terem o sabor doce. E, não se contentando com

\footnotetext{
${ }^{9}$ Todavia, mesmo na sociedade ocidental, estas dicotomizações são bastante recentes. Na França “.... nos séculos XIII, XIV e XV era possível encontrar açúcar em diferentes momentos da refeição: nas sopas, entradas e assados, assim como entre os pratos principais e nas sobremesas. A partir do século XVII, os pratos doces tendem a se concentrar no final das refeições ..." (FLANDRIN, 1998b, p. 654). "Antes do final do século [XVII], a prática de adoçar carnes, aves, peixes e legumes é considerada uma falta de gosto; daí em diante o açúcar só é utilizado com ovos, cereais, na preparação de bolos, ou com frutas, café, chá e chocolate" (FLANDRIN, 1998a, p. 675).

${ }^{10}$ Vide o exemplo dos Mbyá-Guarani (TEMPASS, 2005).
}

Espaço Ameríndio, Porto Alegre, v. 2, n. 2, p. 98-114, jul./dez. 2008. 
isso, os indígenas ainda regavam estes alimentos com mel. Beijus eram regados com mel, bolos de milho acrescidos de mel. E assim em muitas outras comidas. O mel acompanhava tudo, não apenas as comidas: o mel também acompanhava o homem. Por onde se deslocavam, os indígenas carregavam consigo uma cabaça com mel silvestre (SILVA, 2005).

Esta prática alimentar, com acento no sabor doce, foi transmitida pelos indígenas aos colonizadores quando estes se valeram dos sistemas culinários indígenas nos primeiros séculos de "conquista". Cito apenas um exemplo para elucidar este ponto. A farinha de mandioca misturada com mel era um dos pratos mais apreciados pelos colonizadores no período colonial (SILVA, 2005). A farinha de mandioca é, sem dúvida, um alimento indígena. O mel acompanhava o índio. Logo, a farinha de mandioca com mel foi herança dos grupos indígenas. E esse alimento podia ser consumido em qualquer refeição, sempre que se tivesse vontade. A adoção desta comida, de forma cotidiana, não foi nada difícil para os colonizadores portugueses. Basta lembrar que a dicotomia entre pratos doces e salgados é recente. Em Portugal, nos primeiros séculos após os descobrimentos, se adoçava toda e qualquer comida. Tendo açúcar disponível se comia todos os pratos adocicados. Provavelmente seja simplesmente uma coincidência, mas, é muito interessante que os colonizadores sejam oriundos de um sistema culinário onde se enaltece o doce e, chegando ao Brasil, operam nos sistemas culinários dos grupos indígenas, que também adoçam praticamente todos os seus alimentos. "Juntaram a fome com a vontade de comer". E ainda estabelecem aqui a maior indústria açucareira do mundo. Não é à toa que os doces fazem parte da identidade do brasileiro.

Voltemos à questão do não reconhecimento da doçaria indígena. Não é necessário o açúcar para se fazer um doce. Como mostrado, os indígenas possuíam alimentos adocicados e desconheciam o açúcar. A junção do açúcar com os ingredientes nativos, para Freyre (1966 e 1997) e Cascudo (1967, 1972 e 1983), foi criação das portuguesas e africanas. Mas, as indígenas já combinavam, há muito, estes ingredientes com o mel. Assim, advogo que às africanas e portuguesas 
coube o papel de substituir, nestas receitas, o mel dos indígenas pelo açúcar ou melado (mel de engenho) dos colonizadores.

Sob um outro prisma, as portuguesas também adaptaram os ingredientes locais para as receitas já tradicionais de doces portugueses. Contudo, estas receitas eram confeccionadas muito raramente, apenas em ocasiões especiais. Isso porque, por muito tempo, os ingredientes europeus eram raros e caros no Brasil. Segundo Gilberto Freyre (1966), no Brasil Colônia faltavam ovos, leite, manteiga, farinha de trigo, entre muitos outros ingredientes. $E$, diante das receitas tradicionais de Portugal, como seria possível fazer um bolo, ou qualquer outro doce tradicional português sem estes ingredientes? Só raramente, sob altos custos. Mas não podemos esquecer que, seguindo a linha de argumentação, os brasileiros, já naquele período, abusavam dos doces. Logo, esse abuso era do sabor doce dos indígenas. O doce indígena era cotidiano; o Doce português era festivo.

$\mathrm{Na}$ esteira do processo de adaptação do açúcar as frutas tropicais, antes combinadas com mel, surgiu uma outra dicotomização. Os doces civilizados e os doces vulgares; os doces fortes e os doces fracos. Segundo Câmara Cascudo (1967 e 1983) os doces sem açúcar eram vulgares e fracos"1. Os doces sem açúcar são nitidamente indígenas. Assim, especulo, tal qual já havia ocorrido na Europa, os indivíduos se distinguiam através do açúcar ${ }^{12}$. Na Europa era uma distinção de classe social: só os ricos podiam comprar o caro açúcar. No Brasil o açúcar distinguia os "civilizados" dos "selvagens", mesmo se este açúcar fosse combinado com ingredientes nativos, talqualmente os indígenas faziam com o mel.

\footnotetext{
${ }^{11}$ Muitos destes doces (suas receitas) tidos como vulgares e fracos chegaram até os dias de hoje. Mas, hoje não possuem mais o caráter depreciativo. Trajetórias semelhantes à da feijoada. A feijoada, para uns inventada nas senzalas pelos escravos (FRY, 2001), para outros na Europa (CASCUDO, 1983), era considerada comida vulgar. Hoje a feijoada é símbolo da identidade nacional brasileira. Representações vão, receitas ficam. O paladar vence.

${ }^{12} \mathrm{O}$ açúcar foi muito acionado pelas elites enquanto um ícone de distinção social, nos termos expostos por Bourdieu (1985) e por Norbert Elias (1990). Isso porque as diferenças nas cozinhas correm paralelas as distinções de classe. Não somente no que se refere à comida propriamente dita, mas também aos utensílios, à organização e as maneiras à mesa. Como argumenta Jack Goody (1995), a alta cozinha, a cozinha das elites, busca constantemente elementos do "exterior", elementos novos, a fim de se diferenciar das demais. É justamente este o caso do açúcar, um alimento trazido do "exterior", caro e raro. $\mathrm{Na}$ Idade Média ele passou a ser empregado na alimentação dos reis e, pela sua preciosidade, era guardado em cofres (LEAL, 2007). Aos poucos os demais membros das elites passaram a utilizar o açúcar nas suas refeições pelo seu gosto agradável e, principalmente, porque as demais classes sociais não poderiam comprá-lo. Assim, consumir açúcar era expor aos seus pares a sua distinta riqueza. Ao consumir muito açúcar se simbolizava ser muito rico.
}

Espaço Ameríndio, Porto Alegre, v. 2, n. 2, p. 98-114, jul./dez. 2008. 
Assim como a região e o país, em geral, tiveram remédios de botica, alguns, importados da Europa, dos quais, até nos anúncios de jornais, se discriminavam uns tantos, para fidalgos e brancos, e, por isto, caros, diferenciando-se dos rústicos e dos destinados a negros, escravos, plebeus, não só pela apresentação, como pelos sabores, pelos odores, pelos nomes [...], 0 doce, no Nordeste, chegou aos nossos dias, em boa parte, diferenciado de maneira semelhante à daqueles remédios, isto é, em doce fino e em doce popular, tendo chegado a haver dois tipos de doces com características definidas quanto a sabores, cores, odores, apresentação, preço ou valor de ingredientes. Algumas dessas diferenças - culturais em geral, étnico-culturais, algumas, e especificamente econômicas, várias - vêm desaparecendo, de todo, ou sendo substituídas por outras, de caráter apenas econômico. Estas se manifestam, principalmente, nos preços de doces e de bolos de confeitaria e de lojas de bombons ou de produtos industrializados - biscoitos, por exemplo - vendidos a preços demasiadamente altos para a população pobre. Note-se, entretanto, que essa mesma industrialização, por outro lado, vem tornando possível o barateamento de caramelos, havendo assim uma área em que a democratização do doce para párvulos se vem processando com a produção industrial em massa de produtos atraentes para os olhos e o paladar de crianças em geral: ricas e pobres (FREYRE, 1997, p. 43-44).

O Brasil torna-se um país híbrido de doce. Doces indígenas e portugueses; doces cotidianos e festivos; doces selvagens e civilizados; doces fracos e fortes; "doces" e "Doces". Este hibridismo, apesar da inevitável dinâmica alimentar, ainda se faz presente nas receitas de hoje, seja nas técnicas, nos utensílios, nos ingredientes, nas formas de consumir e, por que não, nas representações. No livro "Açúcar: uma sociologia do doce", Gilberto Freyre (1997) apresenta uma série de receitas de bolos e doces coletadas no Nordeste brasileiro. Em um rápido levantamento, das oitenta e sete receitas de bolos que o autor descreve, cinqüenta e quatro contém ingredientes indígenas. Destacamse a mandioca e o milho; trinta e uma receitas com a primeira e dezessete com a segunda. Dez receitas não levam ovos, cinco não usam açúcar e dez são sem manteiga, ingredientes típicos da doçaria 
portuguesa. Já dentre as setenta receitas de doces apresentadas, quarenta e uma contêm ingredientes indígenas. Trinta e uma receitas não levam ovos, quatro não usam açúcar e trinta e oito são sem manteiga. Lamento que este levantamento se resuma aos ingredientes, pois não foi possível recolher demais aspectos do sistema culinário.

Mas, as receitas apresentadas por Gilberto Freyre são, na realidade, apenas a parcela registrável das práticas alimentares brasileiras. Como apontam Hernández e Arnáiz (2005), o que se interioriza como tradicional e peculiar de uma cozinha própria é construído a partir das comidas festivas. Os alimentos de festa são raros, requerem mais despesas e tempo de preparação. Os alimentos do cotidiano, ao contrário, são feitos freqüentemente, de forma rápida e barata. Aplicando isso à doçaria brasileira temos que os doces indígenas são cotidianos e os Doces portugueses são festivos. Segundo Ariovaldo Franco (2006), o rotineiro é esquecido e o excepcional é registrado. Assim, os doces indígenas não foram registrados. A participação indígena na doçaria brasileira foi esquecida. E, como só os ricos têm interesse em fixar receitas (CASCUDO, 1967), somente os doces finos, os doces portugueses, foram registrados.

Além disso, outros fatores podem ter contribuído para o não registro da doçaria indígena. Ocorre que, como assinalam vários autores, dentre eles Marshall Sahlins (2003), as carnes evocam o pólo masculino. Basta lembrar que a caça é uma atividade masculina e que, na imensa maioria das sociedades, as mulheres cozinham enquanto os homens assam (LÉPINE, 2003; CASCUDO, 1983). Assam carnes. Ora, os primeiros colonizadores eram, predominantemente, homens. Nos primeiros dois séculos faltaram mulheres brancas no Brasil (FREYRE, 1966). Também os primeiros cronistas do Brasil, de onde são oriundos os dados sobre a alimentação no período pós-descobrimento, são todos homens. Paula Pinto e Silva (2005), ao expor os relatos dos cronistas, apresenta vários depoimentos elogiosos sobre as carnes de caça preparadas pelos indígenas.

Já os doces estão mais relacionados ao pólo feminino.

O doce adquiriu no Brasil um valor simbólico específico. $\mathrm{Na}$ mente brasileira ele está indissociavelmente unido à idéia de ternura, de amor: 
amor da mãe que alimenta seu bebê, da ama preta que amamenta o filho do senhor e cuida dele como se fosse seu, da esposa que prepara doces para o marido, da avó que paparica os netos. É doce que se prepara para as festas; para demonstrar afeto, oferece-se doce à amiga, à visita. Doce é coisa para mulher, tem conotação feminina, embora os homens, de vez em quando, se deixem também seduzir (LÉPINE, 2003, p. 297).

Assim, sendo os primeiros colonizadores e cronistas homens aventureiros viris - não é de se estranhar que existam inúmeros relatos sobre as carnes e raríssimos sobre a doçaria. Os doces - os sabores doces - existiam e eram largamente consumidos, mas não foram registrados.

Por fim, procuramos mostrar neste artigo que, ao contrário do que se divulgava, os indígenas possuíam/possuem uma série de alimentos adocicados e que estes influenciaram a atual doçaria brasileira, contribuindo para o consumo excessivo de doces que hoje constituem um traço identitário dos brasileiros. Ao mesmo tempo procuramos expor as razões para que cronistas e autores clássicos tivessem negligenciado a participação indígena neste processo.

\section{Referências bibliográficas}

BOURDIEU, Pierre. La distinction: critique sociale du jugement. Paris: Ed. de Minuit, 1985.

CASCUDO, Luís da Câmara. História da alimentação no Brasil: cardápio indígena, dieta africana, ementa portuguesa. São Paulo: Companhia Editora Nacional, 1967. v. 1.

Seleta. Rio de Janeiro: José Olympio, 1972.

. História da alimentação no Brasil: cozinha brasileira. Belo Horizonte: Ed. Itatiaia; São Paulo: Ed. da Universidade de São Paulo, 1983. v. 2.

CATHARINO, José Martins. Trabalho índio em terras da Vera ou Santa Cruz e do Brasil: tentativa de resgato ergonológico. Rio de Janeiro: Salamandra, 1995.

COUTO, Cristiana. Arte de cozinha: alimentação e dietética em Portugal e no Brasil (séculos XVII-XIX). São Paulo: Editora Senac São Paulo, 2007. 
MÁRTIN CÉSAR TEMPASS - Os grupos indígenas e os doces brasileiros

DESCOLA, Philippe. Estrutura ou sentimento: a relação com o animal na Amazônia. Revista Mana, Rio de Janeiro, v. 4, n. 1, p. 23-45, 1998.

ELIAS, Norbert. O processo civilizador: uma história dos costumes. Rio de Janeiro: Jorge Zahar Editor, 1990.

FLANDRIN, Jean-Louis. Le goût a son historie. In: PIAULT, Fabrice (Org.). Le mangeur: menus, maux et mots. Autrement, Coll. Mutations/Mangeurs, Paris, p. 147$158,1993$.

Da dietética à gastronomia, ou a libertação da gula. In. FLANDRIN, JeanLouis; MONTANARI, Massimo (Orgs.). História da Alimentação. São Paulo: Estação Liberdade, 1998a. p. 667-688.

Preferências alimentares e arte culinária (séculos XVI-XVIII). In. FLANDRIN, Jean-Louis; MONTANARI, Massimo (Orgs.). História da Alimentação. São Paulo: Estação Liberdade, 1998b. p. 640-666.

FRANCO, Ariovaldo. De caçador a gourmet: uma história da gastronomia. São Paulo: Editora Senac São Paulo, 2006.

FREYRE, Gilberto. Casa-Grande \& Senzala: formação da família brasileira sob o regime de economia patriarcal. 13. ed. brasileira. Rio de Janeiro: José Olympio, 1966.

Açúcar: uma sociologia do doce, com receitas de bolos e doces do Nordeste do Brasil. São Paulo: Companhia das Letras, 1997.

FRY, Peter. Feijoada e soul food 25 anos depois. In: ESTERCI, Neide; FRY, Peter; GOLDEMBERG, Miriam (Org.). Fazendo Antropologia no Brasil. Rio de Janeiro: Dp\&A, 2001. p. 35-54.

GONÇALVES, José Reginaldo Santos. A fome e o paladar: uma perspectiva antropológica. In: Seminário alimentação e cultura. Rio de Janeiro: Funarte, 2002. p. 7-16.

GOODY, Jack. Cocina, cuisine y clase: estudio de sociología comparada. Barcelona: Gedisa Editorial, 1995.

HERNÁNDEZ, Jesús Contreras; ARNÁIZ, Mabel Gracia. Alimentación y cultura: perspectivas antropológicas. Barcelona: Editorial Ariel, 2005.

LEAL, Maria Leonor de Macedo Soares. A história da gastronomia. Rio de Janeiro: Senac Nacional, 2007.

LÉPINE, Claude. Cozinha e dieta alimentar na obra de Gilberto Freyre. In. KOSMINSKY, Ethel Volfzon; LÉPINE, Claude; PEIXOTO, Fernanda Áreas. Gilberto Freyre em quatro tempos. Bauru: EDUSC, 2003. p. 287-302. 
LOKSCHIN, Fernando. Baba de moça: açúcar, dolce vita, il doce far tutto. Revista Estilo Zaffari, Porto Alegre, ano 7, n. 35, dez. 2005. [s/p].

SAHLINS, Marshall. Cultura e razão prática. Rio de Janeiro: Zahar, 2003.

SILVA, Paula Pinto e. Farinha, feijão e carne-seca: um tripé culinário no Brasil colonial. São Paulo: Editora Senac São Paulo, 2005.

TEMPASS, Mártin César. Orerémbiú: a relação das práticas alimentares e seus significados com a identidade étnica e a cosmologia Mbyá-Guarani. 2005. $156 \mathrm{f}$. Dissertação (Mestrado em Antropologia Social) - PPGAS/UFRGS, [2005].

Os Sistemas culinários indígenas no processo de colonização do Brasil. In: I

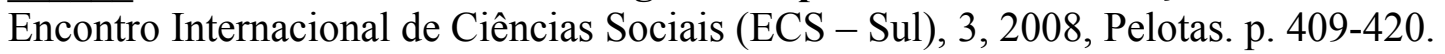

